\title{
The Semantics of Incongruous Collocations in Chimamanda Adichie's Half of a Yellow Sun
}

\author{
Isaiah Aluya \& Edem Samuel \\ http://dx.doi./org/10.4314/ujah.v19i2.8
}

\begin{abstract}
Commenting on the significance of collocation to the study of the language of literature, Spencer and Gregory (1978) assert that the creative writer often realizes some of his effects through the interplay between congruous and incongruous collocations. This assertion is true of Chimamanda Adichie's literary crafts which display a great deal of freedom of choice in collocational patterning. This paper examines incongruous collocations in Adichie's Half of a Yellow Sun, the purpose being to determine her violation of the normal restrictions in the language code in order to establish her own unique paradigms. The paper is germane to the study of language-literature interface in that it provides an avenue for readers to appreciate linguistic breaches in literary discourse.
\end{abstract}

Key words: Chimamanda Adichie, Collocation, Creativity, Incongruity, Prose fiction

\section{Introduction}

The term 'creativity' is derived from the verb 'creative'. Both terms, i.e. creativity and creative are employed in a multiplicity of contexts. Creativity is a subject studied in a number of disciplines ranging from psychology, ethnography and linguistics among others. For example, while psychologists examine creativity in order to determine its connection with the mind and the brain and 
ethnologists study its role in the society; linguists investigate the concept in order to comprehend how language is employed in daily exchanges ("Language and creativity", 2018: 9). Interest in the study of creativity has increased significantly in many sub-fields of linguistics over the years (Jones, 2011) owing to the fact that creativity is fundamental to the study of language as it offers language users the opportunity to express "indefinitely many thoughts and for reacting appropriately in an indefinite range of new situations" (Chomsky, 1965: 6).

Creativity is strongly associated with imagination, innovation, originality and genius. Cook (1998: 205) observes that creativity functions as "patterns of formal features and linguistic idiosyncrasies of particular texts". To Kaufman and Sternberg (2010), a product or thing is creative if it is novel, of high quality and appropriate to the task at hand. To them, novelty refers to the idea that the product of creativity has to be something different, new, or innovative; high quality suggests that such a product needs to be evaluated as good; and finally, appropriateness implies that the creative 'product' or 'thing' has to make sense or be useful for a particular context. Though the subject of creativity is extensive and has been explored from numerous disciplines, the present study approaches the concept from linguistic and literary perspectives.

The two types of creativity within the fields of linguistics and literary criticism are: linguistic and literary creativity. Linguistic creativity refers to the innovative uses of language (Chomsky, 1965). This implies the activity of constructing, recreating and re-interpreting meaning. Conversely, literary creativity entails the violation of the rules of normal language uses in order to create a remarkable local norm distinct from ordinary language (Swann, 2006: 3). To corroborate this delineation, Carter 
and McCarthy (2004) avow that literary creativity is the manipulation of literary devices for communicative and aesthetics purposes. This manipulation according to Leech (1969) may deviate from the generally observed rules of the language in many different ways which could sometimes be obvious or subtle. In this respect, Leech (1969: 5) opines that the creative writer enjoys a unique freedom, among other users of language, "to range over all its communicative resources, without respect to the social or historical contexts to which they belong".

Creativity, be it linguistic or literary, can be explored from the textual, contextual and critical viewpoints. The textual examines the properties of literary language by describing, comparing and analyzing its features; the contextual upholds the view that context and language are inextricable; and as such, priority must be accorded to the context of utterance when analyzing language. Finally, the critical raises questions that border on the values and assumptions embedded in context with a view to exploring creativity ("Language and creativity", 2018: 18-19).The creative utilisation of language in literature has been an extremely worthwhile aspect of linguistics investigations owing to the language and literature interface as each field mutually benefits more from its connection to, rather than its disconnection from, the other (Widdowson, 1975). Being a creative writer of great repute, Chimamanda Adichie's Half of a Yellow Sun (henceforth, HYS) has been the subject of appreciable academic research. We review some of the linguistic studies accomplished on this novel in the next sub-section.

\section{Linguistic studies on Adichie's HYS}

A great deal of research efforts has been dedicated to many aspects of the language used in Adichie's HYS. Some of these efforts to 
characterize Adichie's art include: Jegede (2010), Osunbade (2013), Edokpayi (2014), Chukwu and Igbokwe (2015), Gajir (2016) and Adagbonyin and Aluya (2017), among others. First, Jegede (2010) explores Adichie's HYS from a lexical semantic perspective, the purpose being to determine how the novelist's lexical semantic creation confirms her idiosyncrasies as a writer.

The study indicates that collocation, noun reference, a blend of simple, compound and complex sentences, among others were deployed to project the novelist's unique artistic vision. Adichie draws greatly on these lexical semantic devices in order to communicate her thematic foci to the readers. Her creative manipulation of these devices establishes her linguistic thumb print. Osunbade (2013) is a pragmatic investigation of the implicatures of domestic discourse on Adichie's HYS and Purple Hibiscus. The study, which adopts the Grecian pragmatic theory, aims at identifying the implicatural dimensions that emerge in the novels and determining how they facilitate access to Adichie's thematic concerns. The study is germane because it reveals the writer's utilisation of pragmatic tools in espousing the domestic experiences of Nigerians and Africans as portrayed in the novels.

Edokpayi (2014) examines aspects of lexical style in Adichie's HYS. The analysis examines the significance of literature and literary artist to national security and provides a detailed description of how the resources of language are deployed in a unique style to convey the thematic preoccupations of the novel. Similarly, Chukwu and Igbokwe (2015) investigate how Adichie uses naming to expand and limit the actions of her characters in HYS. Using Leech's (1983) Socio-pragmatics and Pragmalinguistics theory, the analysis demonstrates how Adichie exploits naming in Igbo to create conflict, suspense, and foreshadowing. The study submits that Adichie is not only craft conscious but also 
Igbo-conscious. Gajir (2016) seeks to determine how lexical semantic resources such as additive, causal and temporal conjunctive resources are employed to accomplish cohesion in Adichie's HYS; and how they have been deployed to convey her intended message.

Using Halliday's Systemic Functional Linguistics, the analysis provides explanation about the structural nexus and meanings which aid to enhance a better understanding of the text. Another study that explores Adiche's utilisation of language in HYS is Adagbonyin and Aluya (2017) who investigated the concepts of cohesion and coherence as features of textuality in Adichie's HYS. The study seeks to account for how the writer's thematic foci have been logically presented in an explicit manner. To achieve this, the analysis employs Halliday and Hassan's unified theory of cohesive harmony to unearth the cohesive devices deployed in relating the writer's thematic concern. The study submits that the logical consistency achieved in the text is realized through the interaction between cohesive devices such reference, collocation, synonym and reiteration.

The aforementioned studies, among many others, are some of the efforts by scholars in characterizing Adichie's HYS. Though $H Y S$ has been approached from numerous perspectives, the subject of incongruous collocation is yet to receive critical attention. This lacuna in research forms the basis for this present study which seeks to explore the semantics of incongruous collocations in the text. The next sub-section takes on the subject of English collocation.

\section{Collocation as a Semantic Construct}

'Collocation' is a significant concept in language learning. Its origin can be traced to the work of the British linguist J.R. Firth 
who is cited as one of the first scholars to deal with the concept. Firth, in his study on collocation, declares that "You shall know a word by the company it keeps," and offer the example of the company of the English word "ass," which occurred in a limited set of contexts and in the company of a limited set of adjectives silly, obstinate, stupid, and awful (Palmer, 1976: 94). While adhering strictly to his delineation on collocation as "the company words keep", Firth maintains that collocation meaning is an abstraction at the syntagmatic level and is not directly concerned with the conceptual or idea approach to the meaning of words. He offers the example of the word night where one of its meanings involves its collocability with dark.

As far as definition is concerned, other scholars have worked on collocation and offered different definitions which are replica to that of Firth. For example, Carter (2004: 14) explains collocation as "the co-occurrence of a word with no more than four intervening words". In commenting on the different types of meaning, Leech (1974: 20) makes reference to collocative meaning and defines collocation as "the associations a word acquires on account of the meaning of words which tend to occur in its environment." While Hoey (2005: 5) views collocation as a "psychological association between words up to four words and evidenced by their occurrence together in corporal more often than is explicable in term of random distribution"; Wales (2011: 68) explains in this respect that collocation is the "habitual or expected co-occurrence of words, a characteristic feature of lexical behaviour in language, justifying to its predictability as well as its idiomaticity". From the foregoing, collocation can be observed between lexical items employed in texts and its relation is viewed between individual lexical items, most especially the ones that habitually co-occur with them in the language. Finally, for a word 
to be a collocation, it needs to occur together with others in more than regular frequency (Norgaard, Montoro and Beatrix, 2010). Collocations can be identified for content words (like adjectives, adverbs and nouns) and function words (like articles, pronouns and preposition).

The latter is usually more frequent than the former. Frequent words also have their own repetition patterns (Norgaard, Montoro and Breatrix, 2011) which can be grammatical because they result primarily from syntactic dependencies; or lexical in that the patterns result from the fact that in a given linguistic environment, certain lexical items will co-occur (Carter, 1998: 51). Collocational types vary in English. The two commonest types are congruous/usual and incongruous/unusual collocations. The former refers to strings of lexical items which cohere with other words in similar environment; conversely, the latter deals with the fusing of two or more contradictory semantic features in similar environment. The amalgamation of two contradictory semantic features is what results to collocational clash or breaches in text. When collocational clash or breaches occur, it leads to deviation which aids to a text to achieve foregrounding effect.

Collocations play important roles in lexical cohesion in that they allow texts to "express membership of a group, articulate ideas economically and reduce the processing efforts for readers. Considering the import of collocation in literary discourse, the present article explores Adichie's HYS from the perspective of incongruous collocation, the purpose being to determine her violation of the normal restrictions in the language code in order to establish her own unique paradigms. 


\section{Analysis of Incongruous Collocations in Adichie's HYS}

The following extracts on incongruous collocations reveal the creativity and diversity of the lexico-semantic structuring in Adichie's HYS:

\section{Extract 1}

Yes, we will find her, Olanna said too, and she felt as if they were all scratching desperate fingernails on a hard, scarred wall (pg. 431).

The discourse above captures the Nigerian/Biafran war and its demoralizing effects in the lives of Nigerians. The underlined noun phrase with which Adichie attempts to contextualise the events she presents in this discourse emanates from her exploitation of incongruous collocations. The novelist's choice of the lexical expression "desperate fingernails" results in a seeming collocational clash as "desperate" will not usually be expected to collocate with "fingernails". The literary device Adichie exploits here is known as synecdoche where a part of human body is employed to represent the whole person.

Looking at the normal collocational patterns, we expect the following predictable collocates for "fingernails": sticky, filthy and swollen etc. Adichie, however, employs "desperate fingernails" to refer to Olanna and her several unproductive hunts for her sister, Kainene who could not be found after the war. Olanna, thus, expresses her optimism that one day she would be found. The aberrant collocations exploited here reveals that the freedom Adichie exercises endorses her credence that the possibilities presented by language in artistic creation must be exploited to the fullest. In this regard, she works within a broad collocational geography. The nominal phrase "desperate fingernails" while demonstrating how innovative the novelist is in her collocational 
patterning, specifically reveals her desire to broaden semantic range. The unexpectedness of this collocation creates surprise and therefore becomes semantically marked within the context of the novel.

Incongruous collocation is also deployed to express resentment and disappointment as the extract below establishes:

\section{Extract 2}

She found a guilty pleasure in the humility he had cloaked himself in since Amaka gave birth (pg. 250).

Here, Adichie highlights the theme of infidelity and its psychological effects. What is remarkable about this discourse is her choice of the lexical expression "a guilty pleasure" deployed by Olanna in describing Odenigbo's extra-marital affair. The noun phrase "a guilty pleasure" is an absurd proposition resulting from extreme collocational breaches.

As this collocational expression indicates, Adichie is prepared to combine lexical features regardless of their grammatical classes and/or functions to construct meaning. She is also ready to violate the normal restrictions on their use. For example, in the above discourse, the predictable range of choices that would be available to the reader to cohere with "pleasure" includes "great", "real", "intense" and "immense". The reader is unlikely to choose "guilty" because such choice would disrupt the normal process of communication and leave a gap in his rendering of the text.

However, Adichie has adopted "guilty" because she is writing prose and prose, to some certain extent permits such aberrant use of language. In processing the text, the reader renders the deviation significant. As Leech (1969) has observed, a lot 
depends on the reader's imagination who perceive "some dipper connection which compensates for superficial oddity". Thus, in "a guilty pleasure", the reader identifies an instance of figurative usage (i.e. the use of oxymoron) and understands that, by it, Adichie is referring to a human being (i.e. Odenigbo) who was ashamed having committed a heinous crime. The noun phrase "guilty pleasure" as deployed in the aforementioned extract aids to effectively carve out the image of what is being discussed within the context of the text while also aiding Olanna to express her disappointment and resentment. As for extract 3), incongruous collocation aids to render prominence to discourse subjects. The discourse below illustrates this point:

\section{Extract 3}

She surreptitiously moved so that her inner arm brushed against her breast and closed her eyes at the needles of delicious pains (pg. 50).

The choice of prepositional phrase "of delicious pain" as captured above underscores the violation of selection restriction rule. Our knowledge of co-occurrence patterns tells us the nouns that can cohere with the adjective "delicious". Thus, strings like "delicious meal" and "delicious pastry" are familiar. In her choice of "delicious pains", Adichie merely extends collocational possibility to capture the overwhelming feeling of excitement derived from lovemaking. The fact that the descriptive adjective "delicious" is employed alongside with the noun "pain" is what creates the collocational clash in the discourse. The lexical item "delicious" does not cohere with "pains" as both are two contradictory semantic features. What is delicious cannot be painful and what is painful can equally not be delicious. One, thus witness Adichie's creativity in this discourse in fusing both semantic properties in 
order to render prominence on the subject being discussed. More illustration on the exploitation of incongruous collocation is presented in the next discourse:

\section{Extract 4}

After the growing news - Biafran troops were flushing out the last remnants of the enemy, Nigerian casualties were high, mopping-up operations were concluding- he would fantasize about the army. $\mathrm{He}$ would be like those recruits who went into training camps while their relatives and well-wishers stood by the sidelines and cheered- and who emerged bright-eyed, in brave uniforms stiff with starch, half of a yellow sun gleaming on their sleeves(pg. 243).

The extract above presents a clash between two semantic properties which are deployed to describe a particular phenomenon. The lexical item "brave" by away of collocational prediction selects the following semantic properties: "decision", "action", "fight", "attempts" and "man" as in: fight

$$
\begin{aligned}
& \text { Brave }+ \text { attempts } \\
& \text { action }
\end{aligned}
$$

"Brave uniform" is unusual. It is, in fact, absurd. In making her choice, Adichie seeks to graphologically register the war highlights between the Nigerian and Biafran armies. Ugwu is elated on hearing that the Biafran troops are subduing the Nigerian armies. He wishes he could join the Civil Defense League or the militia to comb for Nigerians hiding in the bush. The incongruous collocational expression "brave uniform" as used in this discourse connotes elegance, fortitude, strength, loyalty, selfless service and resoluteness which epitomize the Biafran troops as well as their personal resolve to combat their enemy. While underscoring the qualities that should characterize the military force in any country, 
the novelist condemns the conflict between both groups owing to its colossal effects.

However, one observes that the next two succeeding extracts (i.e. 5 and 6) show a collocational clash in the combination of "animate" verbs with non-animate entities as presented below:

\section{Extract 5}

The fridge breathed heavily in his ears (pg. 6).

\section{Extract 6}

The hot iron hissed and when he raised it, he saw that half of the sock was glued to it (pg. 14).

As dynamic verbs, the lexical items "breathed" and "hissed" are expected to select animate properties. For "breathed", the predictable collocates (subjects) include "the man", "the woman" and "the boy" etc., as in:

\section{The man}

The woman + breathed

The boy

For "hissed", choices available range from "the students", "the traders" and "the children" etc., as in:

The students

$$
\begin{aligned}
& \text { The traders }+ \text { hissed } \\
& \text { The children }
\end{aligned}
$$

In adopting her own choices, nonetheless, Adichie means to satisfy creative needs. Yet the basic motive is to heighten communicative impact. What she relays in the contexts of these discourses are actions performed by animate entities. As regard "breathed", all living things take air into and out of the lungs to facilitate gas exchange with the internal environment and they also "hissed" to 
express disapproval. By conferring the features of animate entities on inanimate entities, Adichie exploits the device known as personification to describe Ugwu's ignorance and lack of exposure. Ugwu actually has neither seen a fridge nor a pressing iron and does not know how they are used and for what purpose. On getting to the city, he is startled seeing these electrical appliances. Thus, whereas the lexical expression "fridge breathed" describes the vapour that splashed on Ugwu's face when the fridge was opened; "hissed" as used with 'hot iron' relates to the 'sound' which was heard when he attempted pressing his master's sock with the pressing iron. In making the subjects of "breathed" and "hissed" non-animate entities, Adichie means to create a shock at the extent to which ignorance and lack of exposure can affect the mentality of the uneducated.

Commenting on the Nigerian/Biafran crisis and the need to approach public issues from divergent perspectives, Adichie exploits the conversation between Olanna and Alice to register her own opinion below:

\section{Extract 7}

Alice gestured with her tiny hands, and what Olanna had once thought to be an elegant fragility suddenly became a self-absorbed conceit, $\underline{\text { a }}$ luxurious selfishness, Alice spoke as if she alone suffered from the war (pg. 378).

The underlined expression in the extract above supplies our instance of collocational clash in the nominal phrase "a luxurious selfishness". The clash arises from the creative combination of the wrong abstract properties. The nominal paradigms required by the language code could be "surroundings", "hostel" and "apartment" as presented in: 


\section{Hotel \\ Luxurious + Surroundings \\ Apartment}

Adichie chooses "luxurious selfishness" to enable her convey her unique vision. She uses Olanna as a character in the novel to challenge and criticize Alice for approaching issues from her own personal perspective. Alice, who was not the only victim affected by the Nigerian/Biafran crises spoke as if she was the only one. This necessitates Adichie's choice of "luxurious selfishness" to portray Alice's egocentricity. To deal with the collocational breaches in the whole novel would mean going on and on. This is because the feature is all pervading and constitutes the hallmark of Adichie's paradigmatic foregrounding. For reasons of expediency, we have examined few samples of deviant or incongruous collocations across the text which the novelist employs to specifically convey figurative end.

In conclusion, Adichie's novel displays a great deal of freedom of choice in collocational patterning. The novelist's lexical creations differ from "congruous" to "incongruous" collocations. The incongruous collocation, which we have examined, results because she often goes beyond the normal range of choices available to her in the language code or breaks conventions to establish her own unique paradigms. The violation of conventions validates Chapman's (1971: 48) opinion that “... any linguistic utterance involves some tension between the rules on which communication depends and the freedom which the user's unique situation demands". For Adichie, this tension is closely felt because she strives at using the resources of the language code to achieve the best effect. Her creative exploitation of incongruous collocations has a special meaning, which is different and more expressive than the congruous ones. They play a vital role in the 
texture and style of the text. The proliferations of unconventional figurative usages in HYS induce the reader's attention due to their remarkability. While endorsing the text as prose, they aid to decrease the likelihood of boredom and give vivacity to the text.

\author{
Isaiah Aluya \\ Department of English \\ Bingham University, Karu \\ Nassarawa State, Nigeria \\ Isaiah4joy@yahoo.com \\ \& \\ Edem Samuel \\ Department of English \\ Police Academy, Wudil \\ Kano State, Nigeria \\ dmsamuel19@gmail.com
}

\title{
References
}

Asomwan, A.S and Aluya, I. (2017). Cohesion and coherence in Chimamanda Ngozi Adichie's Half of a Yellow Sun. Journal of Humanities Today. 3.1: 11-24.

Adichie, C. N. (2006). Half of a Yellow Sun. Lagos: Farafina.

Carter, R. (1998) 'Common language: Corpus, creativity and cognition'. Language and Literature . 8.3: 195-216.

Carter, R. (2004). Language and creativity: The art of common talk. London: New York: Routledge.

Carter, R. and McCarthy, M. (2004). Talking, Creating: Interactional Language, Creativity and Context. Applied Linguistics. 25.1:62-88. 
Chapman, R. (1973). Linguistics and literature: An introduction to literary stylistics. London: Edward Arnold.

Chukwu, M.E. and Igbokwe, C. (2015). A Pragmatic Analysis of Igbo Names in Adichie's Half of a Yellow Sun. Lwati: A Journal of Contemporary Research. 12.1: Edokpayi, J.N. (2014). National Security in Developing and Sustaining the African Economy: Aspects of linguistic style in Chimamanda Adichie's War Novel, Half of a Yellow Sun. Education and Science Journal of Policy Review and Curriculum Development.4.1:1741-8771.

Cook, G. (1998). 'Linguistics and language teaching' in The encyclopedic dictionary of applied linguistics. Johnson, $\mathrm{K}$. and Johnson, H. (eds). Oxford: Blackwell, 198-207.

Chomsky, N. (1965). Aspects of the theory of syntax. Cambridge: MIT Press.

Gajir, T.H. (2016). Structural Solidarity in Adichie's Half of a Yellow Sun. Ayodabo, O.,

Butari, N.H., Patric, O., and Abraham, O. (eds.) Linguistics, language and literature. Zaria: Izymac Frontz. 563-572.

Hoey, M. (2005).Lexical Priming: A New Theory of Words and Language. UK: Taylor and Francis.

Jegede, R. (2014). The issues of accessibility: A lexico-semantic reading of Chimamanda Ngozi Adichie's Half of a Yellow Sun. Journal of Arts and Contemporary Society. 2.1-9.

Jones, R. H. (2011). "Introduction: Discourse and Creativity." In

R. Jones (eds.). Discourse and Creativity. Pearson: London. $1-14$.

Kaufman, J. C., and Sternberg, R. J. (Eds.).(2010). The Cambridge handbook of creativity. New York: Cambridge University Press.

Language and Creativity (2018, March 20). Retrieved from 
www.open.edu/openlearn/languages/language-andcreativity/content

Leech, G. (1969). A linguistics guide to English poetry. London: Longman.

Leech, G. (1974). Semantics. England: Penguin Books Ltd.

Nørgaard, N., Montoro, R. and Beatrix, B. (2010).Key terms in stylistics. London: Continuum International Publishing Group.

Osunbade, N. (2013). Implicatures of Domestic Discourse in Chimamanda Ngozi Adichie's Purple Hibiscus and Half of a Yellow Sun. Research on Humanities and Social Sciences. 3.21:82-93.

Palmer, F.R. (1976). Semantics. US: Cambridge University Press.

Spencer, J. and Gregory, M. (1978). An Approach to the Study of Style". Linguistics and Style. Eds. N. E. Enkvist et al. London:OUP,1964.73-94.

Wales, K. (2011). A dictionary of stylistics. ${ }^{\text {rd }}$. ed. London: Pearson Education Limited.

Widdowson, H. G. (1975).Stylistics and the teaching of literature. London: Longman. 